\title{
4
}

\section{A construção de um sistema de garantia da segurança alimentar e nutricional}

\section{para o Brasil $^{1}$}

\author{
Maria Sylvia Carvalho de Barros $^{2}$ e Vera Mariza Henriques de Miranda Costa ${ }^{3}$
}

O objetivo do trabalho foi atualizar as informações e refletir a respeito da implantação do Sistema Nacional de Segurança Alimentar e Nutricional (SISAN), criado, em 2006, pela Lei Orgânica da Segurança Alimentar e Nutricional (LOSAN). Analisaram-se artigos acadêmicos, relatórios e documentos oficiais disponíveis e relevantes. O Sistema deve ser estruturado de forma intersetorial, descentralizada, com ampla participação e controle social e sua composição deve incluir órgãos dos diferentes níveis de governo e organizações da sociedade civil. Os Conselhos Municipais e Estaduais de SAN constituem-se instâncias privilegiadas de reflexão e ação sobre todos os componentes do conceito e para a construção, com autonomia, da política de SAN. Verificou-se a necessidade de um papel preponderante dos componentes do nível federal, liderando o processo de constituição do Sistema e estimulando as demais esferas de governo para que assumam sua responsabilidade e contribuam com a definição e a implementação de uma política pública de caráter sistêmico, de garantia, a todos, do Direito Humano à Alimentação Adequada (DHAA) na perspectiva da Soberania e Segurança Alimentar.

Palavras-chave: Segurança Alimentar e Nutricional, Direito Humano à Alimentação Adequada, Soberania Alimentar.

\section{Building a system to guarantee food and nutrition security in Brazil}

The aim of this study was to update information and reflect on the deployment of National System for Food and Nutrition Security, created in 2006 by Organic Law on Food and Nutritional Security (LOSAN). Available and relevant academic papers, reports and official documents were assessed. The system should be structured in an intersectoral and decentralized way, with broad participation and social control. Its composition should include agencies of different levels of government and civil society organizations. Municipal and State Councils are privileged in terms of reflection and action on all concept components. They are also able to construct, autonomously, Food and Nutritional Security Policy. The federal level components should play a key role, leading the system constitution process and stimulating other spheres of government to assume their responsibilities and to contribute to the definition and implementation of a systemic policy, ensuring human right to adequate food in view of Sovereignty and Food Security.

Keywords: Food and Nutritional Security, Human Right to Adequate Food, Food Sovereignty.

${ }^{1} \mathrm{O}$ artigo é parte da tese de doutorado da primeira autora, intitulada "Segurança Alimentar e Nutricional Sustentável: a coordenação de políticas públicas locais na CRSANS Central - São Paulo", Programa de Pós-Graduação em Alimentos e Nutrição, Faculdade de Ciências Farmacêuticas, UNESP, Araraquara, SP, 2013.

2 Professora Doutora do Curso de Nutrição, UNICEP - Centro Universitário Central Paulista, Rua Miguel Petroni no 5.111, CEP 13563-470, São Carlos, SP. Endereço para correspondência: Alameda das Pitangueiras no 61, Parque Faber, São Carlos, SP. CEP 13.561-359. Telefone: 55(16)3412-7486. E-mail: msylvia.barros@gmail.com

${ }^{3}$ Livre Docente, Professora Adjunta Aposentada da Faculdade de Ciências e Letras, UNESP Araraquara; Docente e Pesquisadora do Programa de Mestrado Profissional em Engenharia de Produção, Universidade de Araraquara - UNIARA, Rua Carlos Gomes no 1.217, CEP 14801-340, Araraquara, SP. E-mail: verammcosta@uol.com.br 


\section{INTRODUÇÃO}

A partir de 2010, o direito à alimentação foi incluído entre os direitos sociais fixados no artigo $6 \mathrm{o}$ da Constituição Federal Brasileira. O avanço decorreu da aprovação da Emenda Constitucional 64 (publicada no DOU - Diário Oficial da União de 05 de fevereiro de 2010), após mobilização de movimentos sociais, entidades civis, órgãos públicos e privados, sob a liderança do CONSEA - Conselho Nacional de Segurança Alimentar e Nutricional. Essa foi mais uma conquista no processo de construção de condições adequadas de Segurança Alimentar e Nutricional (SAN) para a população brasileira.

A origem das políticas públicas de alimentação e nutrição no Brasil remonta às décadas de 30 e 40 do século XX [1,2]. Os cientistas que inicialmente se dedicaram ao tema da nutrição no país tiveram importante papel na transformação do "problema alimentar" por eles identificado, em uma agenda de estado. Os primeiros estudos realizados no país já mostraram clara relação entre a situação social e econômica e as más condições de alimentação, indicando como solução ações educativas e racionalização da oferta de alimentos. O Estado, entretanto, assume a execução da política com ações e programas de modelos variados, todos com complexo padrão de execução burocrática, que incluíam a distribuição de refeições (para trabalhadores e estudantes) e de alimentos para diferentes grupos vulneráveis (crianças, gestantes e nutrizes), passando por estratégias de produção e comercialização de alimentos de baixo custo [3].

Esse modelo, de caráter assistencialista, perdurou até a década de 1990, quando começa a se delinear uma nova abordagem para a questão da fome: a da segurança alimentar e nutricional (SAN). Embora o conceito de SAN seja mais antigo, é nesse momento que ele passa a compor a agenda nacional para as questões sociais. Uma evolução conceitual, tanto em nível internacional como nacional, emerge em processo contínuo de discussão, com ampliação de seu escopo [4]. Associa-se a perspectiva do Direito Humano à Alimentação Adequada (DHAA) à busca pela garantia de SAN, o que possibilita agregar princípios e diretrizes que podem significar uma diferenciação do que vinha sendo feito até então [5].
Muitos autores vêm registrando e analisando esse processo. Em meados da década de 1990 e início dos anos 2000, Flavio Valente e Walter Belik revisaram a evolução na construção do conceito de SAN e avaliaram perspectivas de sua transformação em políticas públicas efetivas [4,6]. A partir de 2005, alguns trabalhos abordaram as questões culturais relacionadas às políticas da área [7], as práticas e percepções de atores sociais envolvidos com a implantação da política [8], aspectos metodológicos para a avaliação de programas públicos e divulgaram resultados dessas avaliações [9-12]. Outros analisaram sua interface com os programas de transferência de renda executados no país [13-17] e a importância das articulações necessárias à promoção da intersetorialidade ${ }^{[18,19]}$.

Mais recentemente observam-se debates a respeito das tendências e dos desafios da pesquisa acadêmica na área, dada a diversidade de seus componentes conceituais [20-24], além de reflexões sobre significados e apropriações do conceito [25,26], das formas de medir a segurança e a insegurança [27], da atuação da sociedade civil e da participação social [28]. Trabalhos publicados em 2013 trataram da questão de recursos para o sistema [29], da formação do nutricionista para atuar em SAN [30] e de um comparativo entre as ações desenvolvidas no Brasil e em Portugal [31]. Em 2014, observa-se significativo incremento no número de publicações sobre o tema, destacando-se muitos relatos de experiências e avaliações de iniciativas municipais, a relação com a questão da produção de alimentos - familiar ou agroindustrial [32], a análise dos resultados da Pesquisa Nacional por amostra de Domicilios - PNAD 2013, mostrando tendência de queda da Insegurança Alimentar no país em função da redução das desigualdades sociais [33] e o papel do país na cooperação internacional sobre o tema ${ }^{[34]}$.

Documentos publicados pelo Ministério do Desenvolvimento Social e Combate à Fome (MDS), pelo Instituto de Pesquisa Econômica Aplicada (IPEA) e por organizações não governamentais que trabalham com o tema, como a Ação Brasileira pela Nutrição e Direitos Humanos (ABRANDH) e o Pólis - Instituto de Estudos, Formação e Assessoria em Políticas Sociais - também vêm abordando a questão. 
Segurança alimentar e nutricional: construção do sistema no Brasil. Barros \& Costa

Neste texto procuramos refletir sobre alguns aspectos da construção recente da política de garantia de SAN no Brasil, por considerarmos que os acontecimentos anteriores já foram devidamente revisitados.

\section{FORMULAÇÃO DA POLÍTICA DE SAN}

O marco regulatório desse processo é a LOSAN - Lei Orgânica de Segurança Alimentar e Nutricional, sancionada pelo Presidente da República em setembro de 2006, para assegurar, à população brasileira, o Direito Humano à Alimentação Adequada - DHAA [35]. Um processo amplo de discussão, que envolveu diferentes setores da sociedade brasileira e também foi conduzido pelo CONSEA, deu suporte para o texto final da Lei ${ }^{[36,37]}$.

A LOSAN prevê a implantação do SISAN Sistema Nacional de Segurança Alimentar e Nutricional, que deve ser composto "por um conjunto de órgãos e entidades da União, dos Estados, do Distrito Federal e dos Municípios e pelas instituições privadas, com ou sem fins lucrativos, afetas à segurança alimentar e nutricional" [35]. Seus objetivos incluem a formulação e a implementação de políticas e planos de segurança alimentar e nutricional; o estímulo à integração de esforços entre governo e sociedade civil; e o acompanhamento, monitoramento e avaliação da segurança alimentar e nutricional no País ${ }^{[35-38] .}$

Tanto a sociedade civil organizada quanto o Estado têm, nas últimas duas décadas, atuado para a obtenção de avanços significativos na busca da garantia do DHAA. Entretanto, a garantia desse direito, assim como de outros Direitos Humanos, ocorre ainda de forma irregular e incompleta no Brasil [36].

Uma das dificuldades para seu alcance pode ser decorrente da abrangência dos conceitos relacionados a essa questão e dos diferentes segmentos da sociedade envolvidos. Paulillo et al. ${ }^{[39]}$ afirmam que são cinco os eixos incluídos na noção de SAN: a saúde (dimensões dietética e nutricional); a higiene (garantia de qualidade sanitária); a ecologia (produção e consumo sustentáveis); a autenticidade (valores e tradições culturais); e, por fim, a solidariedade (participação de toda a sociedade, incluídas as parcelas saudáveis e sem risco alimentar e nutricional e os governantes, na conquista da SAN para todos).
O DHAA tem duas dimensões definidas por tratados internacionais de direitos humanos: o direito de estar livre da fome e o direito a uma alimentação adequada. Aspectos como a disponibilidade de alimentos, a adequação dos alimentos disponíveis, a acessibilidade (física e econômica) aos alimentos e a estabilidade do fornecimento estão incluídas nesse conceito. Como parte dos Direitos Humanos, deve ter uma abordagem que respeite as perspectivas da dignidade humana (sendo os indivíduos reconhecidos como titulares de direitos humanos), da prestação de contas ou responsabilização (pressupondo um Estado que age de forma transparente e presta contas de suas ações) e do apoderamento por parte dos indivíduos, das informações e instrumentos necessários à reivindicação e exigência de seus direitos [5].

A LOSAN prevê que a adoção de políticas e ações necessárias para promover e garantir a Segurança Alimentar e Nutricional da população cabem ao Poder Público e destaca que "a alimentação adequada é um direito fundamental do ser humano, inerente à dignidade da pessoa humana e indispensável à realização dos direitos consagrados na Constituição Federal" [35].

É preciso que sejam consideradas diferentes perspectivas - ambientais, culturais, econômicas, regionais e sociais - na implantação das políticas de SAN/DHAA. O poder público deverá respeitar, proteger, promover, prover, informar, monitorar, fiscalizar e avaliar a realização do DHAA, além de garantir os mecanismos para sua exigibilidade [38]. Tais ações devem respeitar a soberania do povo brasileiro e a autonomia de decisões relacionadas a cada um dos aspectos que compõem a Segurança Alimentar.

A construção e a consolidação do SISAN devem levar a importantes mudanças na estrutura política e econômica brasileira. O Sistema deve buscar privilegiar a intersetorialidade, articular e coordenar ações e programas descentralizados e interdependentes nas três esferas de governo, assumindo a relação estado/sociedade civil. Para isso, a estrutura políticoinstitucional brasileira necessitará mais que a simples organização de um sistema de gestão, dada a complexidade das questões que envolvem a SAN e o DHAA. Todos os aspectos do conceito de SAN precisam ser incorporados às ações, que devem envolver o conjunto da sociedade, tanto na condição de agente quanto na de sujeito das medidas que buscam a garantia de SAN/DHAA. A soberania alimentar e a 
possibilidade de modos de vida saudável, resultantes de políticas de caráter universal, são os objetivos finais [37].

A atuação conjunta dos órgãos governamentais (federais, estaduais e municipais) e das organizações da sociedade civil na formulação e implementação de políticas de SAN ocorrerá por meio do SISAN. O acompanhamento, o monitoramento e a avaliação da situação nutricional da população também devem ser responsabilidade da atuação conjunta da sociedade e dos governos. O Sistema definirá direitos e deveres do poder público e da sociedade [40].

É clara a interface das questões da SAN e do DHAA com a área da saúde. A implementação do SISAN remete à extraordinária experiência das últimas décadas na área da saúde, referente ao Movimento da Reforma Sanitária, que resultou na criação e implantação do SUS - Sistema Único de Saúde. A transformação em realidade das propostas construídas coletivamente e sistematizadas na 8 a Conferência Nacional de Saúde desencadeou uma série de mudanças no cenário nacional da saúde, seguindo princípios e diretrizes similares aos hoje propostos para o SISAN. O SUS não é um sistema acabado e permanece em discussão, desenvolvimento e implantação. Após sua criação, em 1988, foram reformuladas as funções do Estado, a sistemática de distribuição de recursos foi revista, várias novas instâncias colegiadas de participação, negociação e decisão foram criadas, envolvendo usuários, gestores, profissionais e organizações da sociedade civil, nos diferentes níveis de governo [41]. Os acertos e desacertos decorrentes da experiência de construção do SUS podem se constituir contribuição relevante para a construção e implantação do SISAN.

\section{ESTRUTURAÇÃO DO SISAN}

De acordo com o estabelecido na LOSAN, o SISAN é composto pela Conferência Nacional (CNSAN), o Conselho Nacional (CONSAN) e a Câmara Intersetorial de Segurança Alimentar e Nutricional (CAISAN), os órgãos e entidades de Segurança Alimentar e Nutricional da União, Estados, Distrito Federal e Municípios e as instituições privadas que tiverem interesse, desde que respeitem critérios, princípios e diretrizes do Sistema [35].

A regulamentação da LOSAN se deu por meio do Decreto no 7.272, de 25 de agosto de 2010, que instituiu a PNSAN - Política Nacional de Segurança
Alimentar e Nutricional e estabeleceu os parâmetros para a elaboração do PLANSAN - Plano Nacional de Segurança Alimentar e Nutricional [35,38].

Além da criação destes marcos regulatórios em SAN, o Ministério do Desenvolvimento Social e Combate à Fome (MDS) tem buscado adotar estratégias de apoio técnico e financeiro aos Estados e Municípios para a implantação do SISAN [40].

Proposto como um sistema público em constante construção, que deve viabilizar a gestão intersetorial e participativa e a articulação voltadas para políticas de SAN, é sua atribuição empenhar-se na otimização das potencialidades de cada setor. Seus objetivos incluem "formular e implementar políticas e planos de SAN, estimular a integração dos esforços entre governo e sociedade civil, bem como promover o acompanhamento, monitoramento e a avaliação da SAN no país" [42].

A opção pelo enfoque sistêmico, de acordo com Renato Maluf, Presidente do CONSEA entre 2007 e 2011, se deu pelos múltiplos determinantes da situação alimentar, bem como pela diretriz da intersetorialidade, que permite a construção de ações e a obtenção de resultados potenciais com efeito sinérgico. No nível federal, são duas as instâncias de coordenação horizontal do Sistema - o CONSEA e a CAISAN. O que o autor identifica, entretanto, como tarefa prioritária, é o estabelecimento de uma forma de articulação vertical entre as diferentes esferas de governo, em um regime de colaboração. Diferente do SUS, um sistema fechado, o SISAN deverá ser constituído como um sistema aberto, de construção dialogada e conjunta com outros sistemas com os quais interage. Essa característica torna a tarefa de sua implantação bastante complexa, já que deve ocorrer de forma conjunta com a construção de uma política nacional para a área. Três componentes são considerados fundamentais, pelo autor, para a constituição das esferas estaduais e municipais do Sistema: o "convencimento e a difusão dos princípios" norteadores, "o papel das políticas federais" e a "organização autônoma da sociedade civil" [43].

A constituição do Sistema prevê que deve ocorrer a adesão de Estados e Municípios, que para isso deverão cumprir as condições mínimas estabelecidas pelo Decreto no 7.272, de 25 de agosto de 2010. Nas instâncias descentralizadas devem ser criados Conselhos de SAN com integrantes que representam a 
Segurança alimentar e nutricional: construção do sistema no Brasil. Barros \& Costa

sociedade civil (2/3) e o poder público $(1 / 3)$, a câmara ou instância intergovernamental de gestão intersetorial e haver compromisso de elaboração do plano de SAN no prazo de um ano.

\section{INTEGRANTES DO SISAN}

No nível federal, o SISAN é composto pela CNSAN, o CONSEA e a CAISAN, aos quais poderão se juntar instituições privadas. A primeira Conferência Nacional de SAN foi realizada no Brasil em 1994, inserida no contexto da criação do primeiro CONSEA (1993) e da inclusão do tema da fome na agenda política estabelecida pelo Movimento de Combate à Fome. Esta primeira Conferência formulou as primeiras diretrizes para a Política Nacional de SAN. A partir de 2003, o tema do combate à fome foi reinserido no debate nacional e o CONSEA foi novamente instituído pelo Governo Federal. O Conselho realizou, em 2004 e 2007, a II e a III Conferências Nacionais de SAN, cujos objetivos principais foram, mais uma vez, a elaboração de diretrizes para a Política Nacional de SAN [28]. A 4a Conferência, realizada em novembro de 2011, aconteceu em um momento em que avanços consideráveis haviam ocorrido em relação à questão da SAN no contexto nacional. O evento, precedido pela realização de Conferências Estaduais e Regionais, teve como eixos temáticos (a) os avanços, ameaças e perspectivas para a efetivação do direito humano à alimentação adequada e saudável e da soberania alimentar; (b) o Plano Nacional de Segurança Alimentar e Nutricional e (c) o Sistema e a Política Nacional de Segurança Alimentar e Nutricional [44]. A CNSAN deve reunir-se a cada quatro anos, respeitando a relação de $1 / 3$ de representantes governamentais para $2 / 3$ da sociedade civil, para indicar ao CONSEA prioridades e diretrizes e para avaliar o SISAN, devendo ser precedida por processos preparatórios regionais/municipais ${ }^{[42]}$. A próxima CNSAN deverá, portanto, realizar-se em novembro de 2015, tendo como tema "Comida de verdade no campo e na cidade: por direitos e soberania alimentar" [45].

O CONSEA, instalado em 30 de janeiro de 2003, tem caráter consultivo e é um instrumento de articulação entre governo e sociedade civil. Assessora o Presidente da República na formulação de políticas e na definição de orientações para garantia do DHAA. Além disso, acompanha e propõe a execução de programas, como Bolsa Família, Alimentação Escolar, Aquisição de Alimentos da Agricultura Familiar e Vigilância Alimentar e Nutricional, entre outros. É formado por representantes da sociedade civil (2/3), ministros de Estado e representantes do Governo Federal (1/3), além de observadores convidados [46]. Suas atribuições principais abrangem a proposição de prioridades e diretrizes, o monitoramento e acompanhamento da Política e do Plano Nacional de SAN originados nas Conferências Nacionais e a mobilização da sociedade civil para a discussão e execução de ações de SAN [47]. O Conselho Nacional tem assumido papel fundamental na estruturação do SISAN. Embora, por seu caráter consultivo, não exerça papel executor de programas e projetos, trabalha para incentivar a participação social na formulação, execução e no acompanhamento da política pública na área de SAN. O CONSEA está à frente, entre outras inúmeras ações, da realização das Conferências, da divulgação de documentos norteadores de discussões e até mesmo de material de apoio sobre a criação de Conselhos de SAN nos municípios ${ }^{[48] .}$

A Câmara Interministerial de SAN reúne 20 ministérios e sua estrutura conta com a Presidência, o Pleno Ministerial (composto por Ministros com assento no CONSEA), o Pleno Executivo (composto pelos suplentes dos Ministros que têm assento no CONSEA), além de Comitês Técnicos (que devem subsidiar a tomada de decisões sobre temas relacionados à SAN). Cabe à CAISAN a elaboração, coordenação, execução e monitoramento da PNSAN e do PLANSAN, bem como a articulação e integração com as esferas estaduais e municipais. As instituições privadas poderão aderir ao SISAN sob condições específicas. A adesão de entidades sem fins lucrativos ocorrerá, segundo o Decreto no 7.272, de 25 de agosto de 2010, por meio de termo de participação, desde que respeitados princípios e diretrizes do Sistema. Já a adesão de entidades com fins lucrativos deverá ser objeto de regulamentação, após consulta ao CONSEA [46].

A constituição do SISAN pressupõe que a estrutura existente no nível federal seja replicada nos estados e municípios.

\section{PARTICIPAÇÃO SOCIAL E SEGURANÇA ALIMENTAR E NUTRICIONAL}

De acordo com Natividade et al. [49], a garantia de que as políticas públicas de SAN contemplem e efetivamente incorporem os interesses da população historicamente excluída dos processos decisórios encontra-se nos mecanismos que preveem a 
participação social em todas as suas etapas, desde a formulação até o controle, passando pela execução e pelo acompanhamento. Mas para que tal participação tenha os resultados desejados, deve possibilitar a apropriação, por parte dos diferentes setores da sociedade, dos conhecimentos e dos instrumentos necessários à defesa de seus interesses. Nesse sentido, o DHAA, parte integrante dos Direitos Econômicos, Sociais e Culturais, percebido como uma perspectiva para garantia de SAN, passa a ocupar lugar de destaque no debate político necessário à busca pela efetiva construção da cidadania. As autoras alertam que é exatamente por meio da participação que se caminha, nesse processo de construção da democracia social (muitas vezes com avanços e retrocessos), em direção da superação de ações autoritárias, assistencialistas, paternalistas e excludentes.

A estrutura existente para o trabalho de consolidação do SISAN conta, além do CONSEA Nacional, com os CONSEAS Estaduais. Muitos municípios já dispõem, também, de alguma estrutura na área e mantém Conselhos Municipais de Segurança Alimentar. É certo que essa estrutura e suas condições de trabalho variam bastante quanto ao grau de organização e as ações em desenvolvimento. As iniciativas nesse sentido, entretanto, devem se intensificar no nível municipal, já que apenas $45 \%$ de um total de 734 municípios que responderam a levantamento realizado pelo MDS em 2014, possuem Conselho Municipal de SAN instalados [50]. Barros e Costa [11], analisando a situação da Comissão Regional de SAN - CRSANS Central do Estado de São Paulo, composta por 26 municípios, encontraram apenas nove que têm legislação de criação do Conselho e apenas dois em que o Conselho existe de fato e é ativo.

Os Conselhos de Políticas Públicas, formados por lideranças e representantes de diversos setores, assumem papel importante por sua capacidade potencial de coordenar a construção de pactos, facilitando o planejamento global e identificando pontos de intersecção e estratégias de intervenção. $\mathrm{O}$ compartilhamento de informações é também estratégico, pois subsidia o processo de tomada de decisões e permite identificar como as decisões de um determinado setor podem minimizar ou potencializar o impacto de medidas tomadas em outro ${ }^{[19]}$.

A estruturação de conselhos gestores de políticas públicas de diferentes áreas e articulados nos três níveis de governo representa a mais efetiva experiência de construção da participação democrática no Brasil. Segundo Tatagiba [52], esses são espaços que permitem o diálogo entre o governo e a sociedade, o que possibilita uma melhor destinação dos recursos públicos em atendimento aos interesses de todos. São também os espaços em que as contradições relacionadas aos diferentes tipos de interesse se manifestam.

Os Conselhos de Segurança Alimentar estaduais e municipais - têm papel essencial em um país com tantas e tão diferentes realidades regionais. É no espaço dos Conselhos que pode ocorrer um diálogo entre a sociedade civil e os representantes dos governos executores das políticas públicas. Nesse mesmo espaço também podem ocorrer diferentes disputas de interesses políticos. Os resultados dessas negociações e desses embates dependem, dessa forma e em grande parte, da formação desses Conselhos.

Dada a importância que adquirem em determinadas realidades locais, observam-se iniciativas no sentido de alterar a dinâmica do poder, por meio de diferentes modelos para sua composição. Além disso, a configuração dos Conselhos - com os representantes designados pelo poder executivo, os escolhidos por usuários e os que representam diferentes organizações - acarretam situações de desigualdades no que se refere a capacidades, importância e legitimidades.

Muitos dos designados para compor os Conselhos carecem, mesmo, de preparo para lidar com as questões técnicas e administrativas inerentes ao trabalho a ser realizado. Tanto representantes de usuários quanto de instituições técnicas podem ainda apresentar dificuldades de compreensão dos conceitos referentes ao jargão típico do tema, distante da realidade cotidiana de alguns ou que não sejam específicos da área de formação de outros [49].

Bandeira ${ }^{[53]}$ alerta que a multiplicação desses mecanismos de participação, especialmente em municípios menores, pode, apesar da intenção positiva, se mostrar contraproducente. Benelli et al. ${ }^{\left[{ }^{54]} \mathrm{chamam}\right.}$ a atenção quanto aos prejuízos causados, em alguns casos, pela demasiada rotatividade de conselheiros, já que o tempo de atuação e a capacitação são importantes formas de garantir um bom trabalho. Também se refere à necessidade de suporte adequado, que deve ser providenciado pela instância de governo ao qual o Conselho está ligado, sem o qual não é possível desenvolver ações administrativas, técnicas e políticas, 
Segurança alimentar e nutricional: construção do sistema no Brasil. Barros \& Costa

incluindo a elaboração de um regimento interno e de planos de gestão e de trabalho.

Kleba et al. ${ }^{[55]}$ defendem a conveniência de uma revisão do papel dos conselhos municipais dadas às dificuldades por eles enfrentadas, entre elas as atribuições burocráticas excessivas, que sobrecarregam os conselheiros e impedem um aprofundamento da avaliação das questões pertinentes às políticas públicas que devem implantar e executar, com metas que avancem e superem as ações de curto prazo. A situação é agravada, na visão dos autores, pela falta de condições efetivas para a realização de um trabalho voluntário, não remunerado, a ser executado, na maior parte das vezes, durante as reuniões e sem um suporte operacional autônomo de qualidade. Além dessas questões, Kronemberguer et al. [56] citam a hegemonia do Executivo nas decisões políticas e uma cultura clientelista que ainda predomina no âmbito municipal. Citando vários outros trabalhos, os autores reafirmam que as dificuldades são muitas e alertam que a legislação (de criação dos Conselhos) não assegura a divisão de poder entre o estado e a sociedade nem a democratização do processo.

Abramovay [57, analisando o PRONAF Programa Nacional de Fortalecimento da Agricultura Familiar, também toca na questão da grande quantidade de Conselhos (de Desenvolvimento Rural) criados nos municípios como condição legal para o repasse dos recursos. Segundo o autor, que fala de uma "profusão" de Conselhos, sua existência não garante participação social efetiva e independente do poder local, embora devam ser reconhecidas suas potencialidades para mudar a dinâmica das decisões políticas nos municípios.

Entre as dificuldades apontadas estariam a participação minoritária da comunidade, a dificuldade de encontrar indivíduos dispostos a participar, o fato de que os próprios Secretários Municipais exercem a presidência de muitos Conselhos, a participação de um mesmo funcionário ou Secretário em diferentes Conselhos, com sobrecarga de trabalho e exigência de presença em muitas reuniões e a necessidade constante de capacitação e assessoramento. Tais dificuldades poderiam ser creditadas à pouca representatividade dos conselheiros e ao seu pouco preparo para a função que devem exercer.

Embora não haja o estabelecimento de uma sistemática ou "receita" para a criação de Conselhos capazes e competentes, não se pode perder de vista, de acordo com o autor, sua principal função: "a coordenação voluntária e planejada dos esforços e capacidades das forças vivas" de um município ou de uma região. Para ele, as iniciativas mais comuns de muitos Conselhos são "parciais e fragmentárias", quando deveriam buscar parcerias e apoio de vários atores sociais que muitas vezes nem pertencem ao cotidiano dos municípios.

\section{PERSPECTIVAS}

Tanto Bandeira [53] quanto Abramovay [57] defendem a necessidade de arranjos regionais, uma vez que a missão dos Conselhos ultrapassa o espaço do município. Entretanto, a inexistência, na estrutura federativa brasileira, de instâncias políticoadministrativas intermediárias entre o Estado e os Municípios e a adoção de diferentes divisões microrregionais, incompatíveis entre si, dificultam a organização e a articulação de ações setoriais que têm como premissa a participação. O enfrentamento, como questões locais, de problemas econômicos e sociais que exigem soluções regionais, acaba por ignorar importantes oportunidades de cooperação na defesa de interesses comuns a vários atores de uma mesma região.

Essa forma de trabalho pressupõe que os Conselhos se configurem como estruturas centrais de redes de relacionamento que permitam a conexão de indivíduos pertencentes a diferentes comunidades e segmentos sociais, para a realização de um trabalho integrado que leve à criação de novos vínculos em busca de um objetivo comum.

A intersetorialidade é princípio fundamental de políticas públicas de desenvolvimento. Elas requerem planejamento integrado, de forma a encarar a tensão natural existente entre as diversas áreas responsáveis pela busca de soluções para os problemas a serem enfrentados ${ }^{[19]}$.

Paulillo et al. [58], em trabalho que aborda redes de políticas públicas locais de SAN em municípios do interior de São Paulo, afirmam que essas políticas necessitam ser submetidas a processos de avaliação, uma vez que se deparam com vários obstáculos. Para os autores, a execução de programas e ações de SAN no nível do município leva à formação de redes voltadas para a inclusão social, que congregam em seu entorno um conjunto de organizações locais. Tais redes influenciam a formação das agendas locais de SAN. 
As redes podem ser formadas por diferentes processos: pela articulação das organizações de base, pela formação de vínculos de interesse comum, pelas afinidades diante de um mesmo interesse e pela articulação de órgãos públicos e instituições de caráter privado ou não ${ }^{[5]}$.

Elas remetem à ideia da ajuda mútua e proporcionam apoio aos indivíduos ou às suas famílias. O potencial de apoio das redes será maior quanto mais fortes e integradas elas forem. Diversos pontos positivos nas relações sociais são reforçados pelas redes, como o compartilhamento de informações e o auxílio em momentos de crise. As organizações sociais comunitárias possibilitam a vivência da participação como um importante fator psicossocial que aumenta a autoconfiança e a capacidade de enfrentar problemas [60].

A intersetorialidade pode ser promovida por meio de uma abordagem matricial, a partir dos problemas. A territorialização (divisão em bairros e territórios) possibilita a definição de projetos intersetoriais que não modificam as estruturas administrativas já existentes, mas as envolvem. Também pode ocorrer pela criação de redes de parcerias que articulem os diferentes setores na busca da solução de problemas prioritários de uma determinada população que vive em um território [61].

A promoção da inclusão social em uma realidade multifacetada, com diferenças regionais e de forma abrangente como pressupõe a garantia de SAN e do DHAA, não pode prescindir da adoção de políticas participativas, da formação e do envolvimento de redes de organizações sociais locais e intersetoriais, geradoras de cidadania [39].

É exatamente nesse ambiente que todas as questões relacionadas à SAN e à garantia do DHAA precisam ser discutidas. É a sociedade, participando efetivamente do processo, que deverá, com autonomia, decidir sobre as diretrizes das políticas de SAN a serem adotadas no âmbito municipal, regional e nacional.

\section{CONSIDERAÇÕES FINAIS}

A conquista da SAN pressupõe o desenvolvimento de um conjunto de ações vinculadas a vários setores. Além daquelas inerentes à cadeia de produção agroalimentar (agroindústria, sistemas de distribuição, comercialização e consumo), estão aí incluídas ações para o atendimento de situações emergenciais de combate à fome e à miséria, de vigilância alimentar e nutricional, de garantia da qualidade sanitária dos alimentos e de valorização da cultura tradicional, com incentivo à retomada de hábitos alimentares saudáveis. E, como pilares de todas essas ações, as políticas relacionadas à economia e às condições de renda e emprego [20].

Superada a pobreza extrema e com a exclusão do país do Mapa da Fome das Nações Unidas [62], novas perspectivas para a SAN podem ser abordadas com maior atenção, como a soberania alimentar. Essa perspectiva deve perpassar as discussões e decisões sobre todo esse conjunto de questões afetas a SAN.

O conceito de soberania alimentar [63], fundamental para o avanço das políticas que favorecem estilos de vida saudáveis, inclui liberdade de decisão, por parte da população e de seus representantes quanto aos alimentos que se deseja produzir e consumir, à forma como essa produção deve ocorrer, ao que se pretende valorizar e incentivar em relação aos hábitos alimentares.Todas essas questões devem ser debatidas contínua e intensivamente, com apoio técnico e ampla participação social, para que se possa definir e atualizar permanentemente a direção das políticas públicas de SAN.

Num país que tem no agronegócio exportador um de seus pilares de sustentação econômica, essas discussões não ocorrem de forma simples ou espontânea. Os diferentes setores da sociedade devem, ocupando os espaços que lhes cabem na estrutura social e política, atuar na defesa de suas necessidades e interesses.

Precisam ser discutidas questões como o modelo tecnológico de produção agrícola (acesso à terra, às sementes e à água, agricultura familiar, monocultura, utilização intensiva de agrotóxicos, produção e comercialização de alimentos orgânicos, tradicionais, regionais e transgênicos); industrialização de alimentos e seus diferentes níveis de processamento, boas práticas nutricionais, estratégias de marketing e rotulagem informativa ao consumidor; redes de comercialização (comércio local, feiras de produtores, médios e grandes varejistas); resgate de alimentos e preparações tradicionais e regionais e educação alimentar, entre tantas outras questões. 
Segurança alimentar e nutricional: construção do sistema no Brasil. Barros \& Costa

Os espaços e as instâncias que compõem o SISAN são privilegiados para as discussões sobre Soberania e Segurança Alimentar. A construção do SISAN foi apenas iniciada e há um longo caminho a ser percorrido. Pela própria essência dinâmica do Sistema proposto, ele deverá se constituir sempre como uma obra em andamento, fruto do trabalho de muitos e diversos atores sociais.

Os órgãos estabelecidos no nível federal para atuarem com a política de SAN - CNSAN, CONSAN e CAISAN - têm a responsabilidade de liderar esse processo, sensibilizando, encorajando e estimulando as demais esferas de governo para que assumam o compromisso e os encargos que lhes cabem no percurso a ser trilhado para a construção do SISAN.

Estados e prefeituras, uma vez engajados na busca pela garantia de SAN, poderão contribuir de forma efetiva para a consolidação de um Sistema plural, intersetorial, participativo, descentralizado, capaz de cumprir as tarefas de discutir todas as questões que impedem a realização do direito à alimentação e de buscar e propor soluções para resolvê-las.

Esse não é um processo simples e nem tampouco célere. Requer o empenho e a perseverança dos órgãos de governo, a cooperação de entidades da sociedade civil, a contribuição de pesquisadores e a participação dos cidadãos. A assimilação de todas as nuances do conceito de SAN requer mais do que um trabalho conjunto, uma postura transetorial, que permita agregar conhecimentos e experiências de forma que governo e sociedade civil, num processo de transformação da realidade, possam, de fato, garantir a todos o Direito Humano à Alimentação Adequada.

\section{REFERÊNCIAS}

[1] Coimbra MA, Meira JFP, Starling MBL. Comer e aprender: uma história da alimentação escolar no Brasil. Belo Horizonte: INAE; 1982.

[2] L'Abbate S. As políticas de alimentaçäo e nutriçäo no Brasil - I - Período de 1940 a 1964. Rev. Nutr. 1988;1(2):87138.

[3] Barros MSC, Tartaglia JC. A política de alimentação e nutrição no Brasil: breve histórico, avaliação e perspectivas. Aliment. Nutr. [internet]. 2009 [acesso em 19 set 2013];14(1):109-21. Disponível em: http://servbib.fcfar.unesp.br/seer/index.php/alimentos/article/viewA rticle/847
[4] Maluf RS, Menezes F, Valente FL. Contribuição ao tema da segurança alimentar no Brasil. Rev Cad Debate. 1996;4:66-88.

[5] Burity V, Franceschini T, Valente F, Recine E, Leão M, Carvalho MF. Direito humano à alimentação adequada no contexto da segurança alimentar e nutricional [internet]. Brasilia (DF): ABRANDH; 2010 [acesso em 20 set 2013]. Disponível em: http://abrandh.org.br/download/20101101121244.pdf

[6] Belik W. Perspectivas para segurança alimentar e nutricional no Brasil. Saúde Soc. 2003;12(1):12-20.

[7] Freitas MCS, Pena PGL. Segurança alimentar e nutricional: a produção do conhecimento com ênfase nos aspectos da cultura. Rev. Nutr. 2007;20(1):69-81.

[8] Assão TY, Cordeiro AA, Costa C, Cervato AM. Práticas e percepções acerca da segurança alimentar e nutricional entre os representantes das instituições integrantes de um centro de referência localizado na região do Butantã, município de São Paulo. Saúde e Soc. 2007;16(1):102-16.

[9] Santos SMC, Santos LMP. Avaliação de políticas públicas de segurança alimentar e combate à fome no período de 1995-2002: 1 - abordagem metodológica. Cad Saúde Pública. 2007;23(5):1029-40.

[10] Santos LMP, Araújo MPN, Martins MC, Veloso IS, Assunção MP, Santos SMC. Avaliação de políticas públicas de segurança alimentar e combate à fome no período 19952002: 2 - Programa de Alimentação do Trabalhador. Cad Saúde Pública. 2007;23(8):1931-45.

[11] Martins MC, Santos LMP, Santos SMC, Araújo MPN, Lima AMP, Santana LAA. Avaliação de políticas públicas de segurança alimentar e combate à fome no período 1995-2002. 3 - O Programa Nacional de Controle da Deficiência de Vitamina A. Cad Saúde Pública. 2007;23(9):2081-93.

[12] Santos LMP, Santos SMC, Santana LAA, Henrique FCS, Mazza RPD, Santos LAS, et al. Avaliação de políticas públicas de segurança alimentar e combate à fome no período 19952002: 4 - Programa Nacional de Alimentação Escolar. Cad Saude Pública. 2007;23(11):2681-93.

[13] Burlandy L. Transferência condicionada de renda e segurança alimentar e nutricional. Cienc. Saude Coletiva. 2007;12(6):1441-51.

[14] Segall-Corrêa AM, Marin-Leon L, Helito H, PérezEscamilla R, Santos LMP, Paes-Sousa R. Transferência de renda e segurança alimentar no Brasil: análise dos dados nacionais. Rev. Nutr. 2008;21:39s-51s. 
Segurança alimentar e nutricional: construção do sistema no Brasil. Barros \& Costa

[15] Traldi DRC, Almeida LMMC, Ferrante VLSB. Repercussões do Programa Bolsa Família no município de Araraquara, SP: um olhar sobre a segurança alimentar e nutricional dos beneficiários. Interações Campo $\mathrm{Gd}$. 2012;13(1):23-37.

[16] Ramos CI, Cuervo MRM. Programa Bolsa Família: a interface entre a atuação profissional e o direito humano a alimentação adequada. Ciênc. Saúde Coletiva. 2012;17(8):2159-68.

[17] Cotta RMM, Machado JC. Programa Bolsa Família e segurança alimentar e nutricional no Brasil: revisão crítica da literatura. Rev. Panam. Salud Pública. 2013;33(1):54-60.

[18] Mafra LAS, Naves FL. Gestão de políticas sociais: a importância das articulações instituicionais e setoriais em programas de segurança alimentar e nutricional. Cad. EBAPEBR. 2009;23;0(1):34-49.

[19] Burlandy L. A construção da política de segurança alimentar e nutricional no Brasil: estratégias e desafios para a promoção da intersetorialidade no âmbito federal de governo. Ciênc. Saúde Coletiva. 2009;14(3):851-60.

[20] Prado SD, Gugelmin SÂ, Mattos RA, Silva JK, Olivares PSG. A pesquisa sobre segurança alimentar e nutricional no Brasil de 2000 a 2005: tendências e desafios. Ciênc. Saúde Coletiva. 2010;15(1):7-18.

[21] Anjos LA, Burlandy L. Construção do conhecimento e formulação de políticas públicas no Brasil na área de segurança alimentar. Ciênc. Saúde Coletiva. 2010;15(1):19_ 22.

[22] Bosi MLM. Desafios na interface pesquisa-construção do direito humano à alimentação: reflexões no âmbito da segurança alimentar e nutricional. Ciênc. Saúde Coletiva. 2010;15(1):22-4.

[23] Proença RPC. Da pesquisa sobre segurança alimentar e nutricional no Brasil ao desafio de criação de comitês de alimentação e nutrição. Ciênc. Saúde Coletiva. 2010;15(1):24 6.

[24] Castro LMC. Pesquisar sobre segurança alimentar e nutricional no Brasil: a que viemos? Ciênc. Saúde Coletiva. 2010;15(1):26-8.

[25] Costa CGA. Segurança alimentar e nutricional: significados e apropriações [internet]. São Paulo: Annablume; 2011 [acesso em 18 set 2013]. Disponível em: http://bases.bireme.br/cgi-bin/wxislind.exe/iah/online
[26] Costa CA, Bógus CM. Significados e apropriações da noção de segurança alimentar e nutricional pelo segmento da sociedade civil do Conselho Nacional de Segurança Alimentar e Nutricional. Saúde e Soc. 2012;21(1):103-14.

[27] Kepple AW, Segall-Corrêa AM. Conceituando e medindo segurança alimentar e nutricional. Ciênc. Saúde Coletiva. 2011;16(1):187-99.

[28] Burlandy L. A atuação da sociedade civil na construção do campo da Alimentação e Nutrição no Brasil: elementos para reflexão. Ciênc. Saúde Coletiva. 2011;16(1):63-72.

[29] Custódio MB, Yuba TY, Cyrillo DC. Food and nutrition security policy in Brazil: an analysis of resource allocation. Rev. Panam. Salud Pública. 2013;33(2):144-50.

[30] Vieira VL, Utikava N, Cervato-Mancuso AM. Atuação profissional no âmbito da segurança alimentar e nutricional na perspectiva de coordenadores de cursos de graduação em Nutrição. Interface - Comum. Saúde Educ. 2013;17(44):15770 .

[31] Vieira VL, Gregório MJ, Cervato-Mancuso AM, Graça APSR. Ações de alimentação e nutrição e sua interface com segurança alimentar e nutricional: uma comparação entre Brasil e Portugal. Saúde e Soc. 2013;22(2):603-7.

[32] Gazolla M. Segurança alimentar e nutricional e agroindústrias familiares: políticas públicas e ações locais. Segur. Aliment. Nutr. 2014;21:527-40.

[33] Hoffmann R. Brasil, 2013: mais segurança alimentar. Segur. Aliment. Nutr. 2014;21:422-36.

[34] Maluf RS, Prado B. Atuação brasileira na América Latina e Caribe relacionada com a soberania e segurança alimentar e nutricional. Rio de Janeiro: CERESAN; 2015 (Textos para Discussão no -8 ).

[35] Brasil. Lei no 11.346, de 15 de setembro de 2006. Cria o Sistema Nacional de Segurança Alimentar e Nutricional SISAN com vistas em assegurar o direito humano à alimentação adequada e dá outras providências. Diário Oficial da União; 2006.

[36] Valente FLS, Beghin N. Realização do direito humano à alimentação adequada e a experiência brasileira: subsídios para a replicabilidade. Brasília: FAO; 2006.

[37] Pinheiro ARO. Reflexões sobre o processo histórico/político de construção da lei orgânica de segurança alimentar e nutricional. Segur. Aliment. Nutr. 2008;15(2):115. 
Segurança alimentar e nutricional: construção do sistema no Brasil. Barros \& Costa

[38] Brasil. Decreto no 7.272, de 25 de agosto de 2010. Regulamenta a Lei no 11.346, de 15 de setembro de 2006, que cria o Sistema Nacional de Segurança Alimentar e Nutricional - SISAN com vistas a assegurar o direito humano à alimentação adequada, institui a Política Nacional de Segurança Alimentar e Nutricional - PNSAN, estabelece os parâmetros para a elaboração do Plano Nacional de Segurança Alimentar e Nutricional, e dá outras providências. Diário Oficial da União; 2010.

[39] Paulillo LF, Almeida LM. Redes de segurança alimentar e agricultura familiar: a merenda escolar como instrumento de desenvolvimento local. Cad. Debate. 2005;11(1):45-67.

[40] Ministério do Desenvolvimento Social e Combate à Fome. Sistema Nacional de Segurança Alimentar e Nutricional - SISAN: Diagnóstico de implantação no âmbito estadual. 2010 [acesso em 20 set 2013]. Disponível em: http://www.mds.gov.br/saladeimprensa/eventos

[41] Viana ALD, Lima LD, Oliveira RG. Descentralização e federalismo: a política de saúde em novo contexto - lições do caso brasileiro. Ciênc. Saúde Coletiva. 2002;7(3):493-507.

[42] Conselho Nacional de Segurança Alimentar e Nutricional. Sistema Nacional de Segurança Alimentar e Nutricional [internet]. Brasília (DF); 2013 [acesso em 17 set 2013]. Disponível em: http://www2.planalto.gov.br/consea

[43] Ministério de Desenvolvimento Social e Combate à Fome (BR). Oficina Nacional - Construindo o Sistema Nacional de Segurança Alimentar e Nutricional. Brasília (DF): SESAN; 2009.

[44] Conselho Nacional de Segurança Alimentar e Nutricional. Eixos Temáticos - 4a Conferência Nacional de Segurança Alimentar e Nutricional [internet]. Brasília (DF); 2015 [acesso em 15 out 2015]. Disponível em: http://www4.planalto.gov.br/consea/conferencia/sobre-aconferencia/eixos-tematicos

[45] Conselho Nacional de Segurança Alimentar e Nutricional. Caderno de Orientações 5a Conferência Nacional de Segurança Alimentar e Nutricional. Brasília (DF); 2015 [acesso em 17 mai 2015]. Disponível em: http://www4.planalto.gov.br/consea/eventos

[46] Brasil. Ministério do Desenvolvimento Social e Combate à Fome. Sistema Nacional de Segurança Alimentar e Nutricional (SISAN) - Avanços e Desafios na Gestão do Sistema [internet]. 2013 [acesso em 24 aug 2013]. Disponível em: http:/ /www.mds.gov.br

[47] Conselho Nacional de Segurança Alimentar e Nutricional [internet]. Brasília; c2013 [acesso em 15 out 2014]. Disponível em: http://www2.planalto.gov.br/consea
[48] Conselho Nacional de Segurança Alimentar e Nutricional. Como criar o Conselho Municipal de Segurança Alimentar e Nutricional [internet]. Brasília; 2011 [acesso em 10 ago 2013]. Disponível em: http://www2.planalto.gov.br/consea

[49] Natividade MO, Silva MES, Rangel SP. Cidadania e direito humano à alimentação adequada no Brasil: problematizações. Sociais e Humanas. 2009;12;22:77-89.

[50] Ministério do Desenvolvimento Social e Combate à Fome. Mapeamento de segurança alimentar e nutricional nos estados e municípios - resultados preliminares. 2015 [acesso em 17 mai 2015]. Disponível em: http://www.mds.gov.br/segurancaalimentar/caisan

[51] Barros MSC, Costa VMHM. Conselhos municipais de segurança alimentar na CRSANS Central SP. Public Health Nutrition. 2012;16 Spe No:157-8.

[52] Tatagiba L. Conselhos gestores de políticas públicas e democracia participativa: aprofundando o debate. Rev. Sociol. e Política. 2005;25:209-13.

[53] Bandeira P. Participação, articulação de atores sociais e desenvolvimento regional. Brasília: Ipea; 1999.

[54] Benelli SJ, Costa-Rosa A. Conselhos municipais: prática e impasses no cenário contemporâneo. Psicol. em Estudo. 2012;17(4):577-86.

[55] Kleba ME, Matielo A, Comerlatto D, Renk E, Colliselli L. O papel dos conselhos gestores de políticas públicas: um debate a partir das práticas em Conselhos Municipais de Chapecó (SC). Ciênc. Saúde Coletiva. 2010;15(3):793-802.

[56] Kronemberger TS, Tenório FG, Dias AF, Barros ACR. Os Conselhos Municipais de Políticas Públicas sob o olhar da comunidade: uma experiência de extensão universitária. Desenvolvimento em Questão. 2012;10(21):146-77.

[57] Abramovay R. Conselhos além dos limites. Estudos Avançados. 2001;15(43):121-40.

[58] Paulillo LFO, Almeida LMMC. Gestão de redes de políticas públicas locais de segurança alimentar: uma análise comparativa dos municípios de Campinas, Araraquara e Catanduva. Gest. Prod. 2011;18(4):853-68.

[59] Ribas ERS, Ribas Júnior FB. Organizações de base, redes intersetoriais e processos de desenvolvimento local: o desafio da sustentabilidade [internet]. Bogotá: RedEAmerica; 2014 [acesso em 05 jun 2014]. Disponível em: http://prattein.com.br/home/dados_anexos/154.pdf. 
Segurança alimentar e nutricional: construção do sistema no Brasil. Barros \& Costa

[60] Andrade GRB, Vaitsman J. Apoio social e redes: conectando solidariedade e saúde. Ciênc. Saúde Coletiva. 2002;7(4):925-34.

[61] Junqueira LAP. A gestão intersetorial das políticas sociais e o terceiro setor. Saúde Soc. 2004;13(1):25-36.
[62] Food and Agriculture Organization. FAO Hunger Map [internet]. Roma; 2014 [acesso em 17 mai 2015]. Disponível em: http://www.fao.org/economic/ess/ess-fs/en/

[63] Souza AS. Um debate acerca da soberania alimentar e da agroecologia: um desafio de percepção e de prática. Ou, de que lado é o meu quintal? Revista Pegada, 2009;10(1):113-33. 